15

\title{
Разработка технологических принципов создания системы микрофокусных рентгеновских трубок на основе кремниевых автоэмиссионных нанокатодов
}

\author{
(С) Н.А. Дюжев, ${ }^{1}$ Г.Д. Демин, ${ }^{1,}{ }^{\mp}$ Н.А. Филиппов, ${ }^{1}$ И.Д. Евсиков, ${ }^{1}$ П.Ю. Глаголев, ${ }^{1}$ М.А. Махиборода, ${ }^{1}$ \\ Н.И. Чхало, ${ }^{2}$ Н.Н. Салащенко, ${ }^{2}$ С.В. Филиппов, ${ }^{3}$ А.Г. Колосько, ${ }^{3}$ Е.О. Попов, ${ }^{3}$ В.А. Беспалов ${ }^{1}$
}

\author{
${ }^{1}$ Национальный исследовательский университет „МИЭТ“, \\ 124498 Зеленоград, Москва, Россия \\ ${ }^{2}$ Институт фоизики микроструктур РАН, \\ 607680 Нижний Новгород, Россия \\ ${ }^{3}$ Физико-технический институт им. А.Ф. Иофффе РАН, \\ 194021 Санкт-Петербург, Россия \\ I e-mail: gddemin@edu.miet.ru
}

Поступило в Редакцию 28 марта 2019 г.

В окончательной редакции 28 марта 2019 г.

Принято к публикации 15 апреля 2019 г.

\begin{abstract}
Обсуждены технологические перспективы создания системы микрофокусных рентгеновских трубок с применением кремниевых автоэмиссионных нанокатодов. Проведен численный анализ автоэмиссионного тока с наноразмерного полупроводникового катода, регулируемого напряжением на сеточном электроде, на основе чего предложена схема управления элементами матрицы автоэмиссионных катодных узлов. Измерены вольт-амперные характеристики кремниевых автоэмиссионных нанокатодов, которые демонстрируют хорошее согласие с предполагаемыми теоретическими оценками автоэмиссионного тока. Проведен полный технологический цикл разработки элементов микрофокусных рентгеновских трубок — набора автоэмиссионных катодных узлов и набора анодных узлов. Полученные результаты могут быть использованы при создании систем микрофокусных рентгеновских трубок для нанолитографического оборудования нового поколения.
\end{abstract}

Ключевые слова: автоэлектронная эмиссия, мягкое рентгеновское излучение, матрица автоэмиссионных катодных узлов, микрофокусная рентгеновская трубка, кремниевые полевые нанокатоды.

DOI: 10.21883/JTF.2019.12.48479.137-19

\section{Введение}

В настоящее время в различных областях науки и техники остро ощущается необходимость в миниатюрных рентгеновских источниках, обладающих низким энергопотреблением, возможностью сканирования рентгеновским лучом с быстрой перестройкой частоты излучения, а также малым временем подготовки к работе. Подобные источники рентгеновского излучения востребованы для целого спектра практических применений, таких как медицинская техника, оборудование для рентгенофлуоресцентного анализа, системы безопасности и противодействия терроризму и т. д. В практических приложениях очень привлекательно и перспективно использование в рентгеновских источниках автоэмиссионного катода в качестве альтернативы традиционному накальному эмиттеру. Прибор на основе холодного автоэмиссионного катода обеспечивает лучшее быстродействие, более широкий температурный диапазон и общую миниатюризацию. Однако в контексте рентгеновских источников, главным преимуществом наноразмерного автоэлектронного эмиттера является узкий электронный пучок, позволяющий при достаточной интенсивности получать малые фокусные пятна на мишени. В зависимости от конкретного применения в качестве источника электронов может быть использован как одиночный автоэмиссионный катод, так и массив таких эмиттеров, позволяющий достичь высоких суммарных значений катодного тока [1]. Дополнительным шагом к миниатюризации рентгеновского источника является использование прострельной мишени, совмещенной с выходным рентгеновским окном [2]. Такая мишень конструктивно состоит из тонкопленочного металлического анода на кремниевой мембране, в котором под воздействием электронного пучка формируется рентгеновское излучение. Технология микроэлектромеханических систем (МЭМС) является наиболее перспективной для ее формирования, поскольку позволяет снизить общую себестоимость и повысить технологичность процесса изготовления рентгеновских окон. Для задач рентгеновской литографии особенно привлекательной является идея разработки массива микрофокусных рентгеновских трубок (МРТ) на основе матрицы автоэмиссионных катодных узлов $(\mathrm{AКУ),} \mathrm{каждый} \mathrm{из} \mathrm{которых} \mathrm{состоит} \mathrm{из} \mathrm{острийного}$ кремниевого нанокатода, управляемого шиной сеточного электрода [3-5]. Непосредственная практическая реализация такой концепции требует как серьезной технологической проработки конструкции матрицы АКУ 


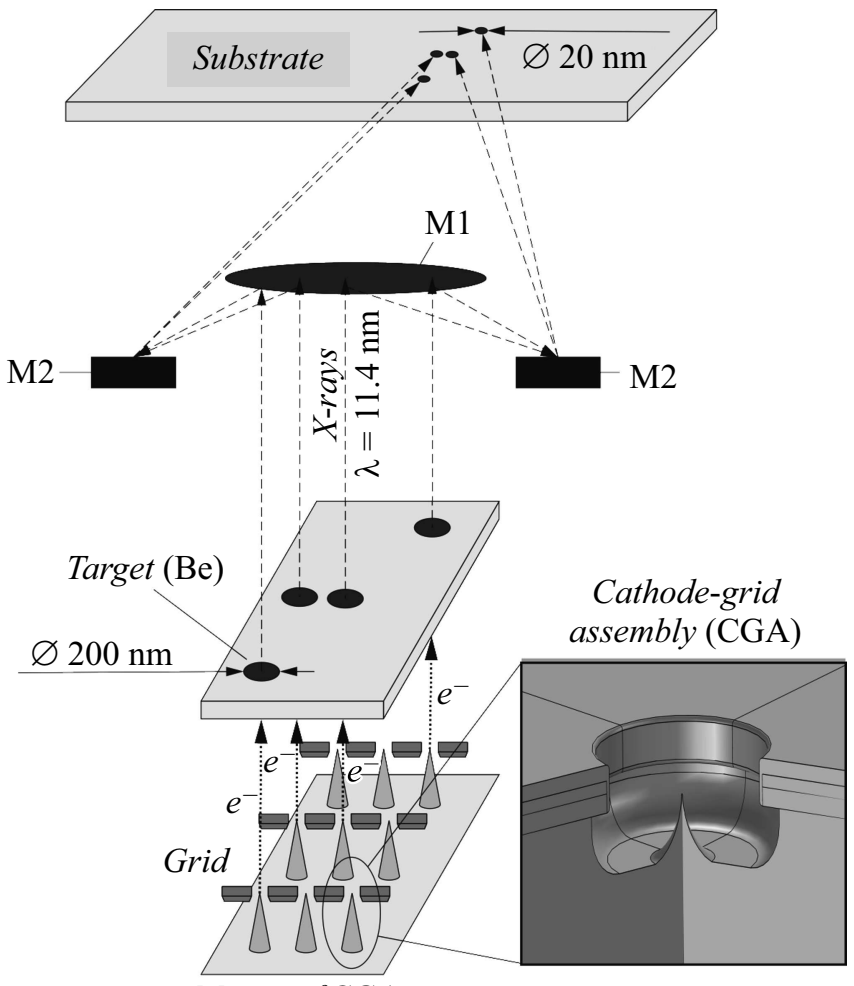

Matrix of CGA

Рис. 1. Схематическое изображение системы МРТ на основе управляемой матрицы АКУ, где M1, M2, М3 - многослойные интерференционные зеркала $\mathrm{Mo}(\mathrm{Ru}) / \mathrm{Be}$.

на базе МЭМС технологии, так и электрической схемы ее управления для создания топологического рисунка. $\mathrm{B}$ настоящей работе описаны как теоретические, так и практические результаты, полученные нашей группой в направлении разработки системы микрофокусных рентгеновских трубок с применением МЭМС технологии создания кремниевых автоэмиссионных кремниевых нанокатодов.

\section{1. Концепция и технология создания системы МРТ на основе матрицы AKY}

На рис. 1 представлено схематическое изображение системы МРТ на основе матрицы кремниевых АКУ. Автоэмиссионный ток с каждого элемента матрицы (кремниевого автоэмиссионного нанокатода) контролируется запирающим напряжением на соответствующих шинах сеточных электродов. Прострельная мишень выполнена из рентгенопрозрачной бериллиевой мембраны, расположенной на утоненной кремниевой пластине толщины $400 \mathrm{~nm}$ с набором отверстий (анодных узлов). Ранее в работе [6] нами было показано, что выбор толщины пленки бериллия в диапазоне от 100 до $200 \mathrm{~nm}$ позволяет получить на выходе из мишени наиболее эффективную конверсию электронной энергии в мягкое рентгеновское излучение с длиной волны $11.4 \mathrm{~nm}$ при напряжении на аноде менее $4 \mathrm{kV}$. Рентгенооптическая система МЭМС зеркал М1 и М2 на основе многослойных структур $\mathrm{Mo}(\mathrm{Ru}) / \mathrm{Be}$ с высоким коэффициентом отражения (более $70 \%$ ) позволяет улучшить разрешающую способность выходящего из прострельной мишени рентгеновского излучения практически в 10 раз, что открывает путь к уменьшению диаметра рентгеновского пучка до 20 mn и ниже [7].

\section{1. Описание технологии формирования матрицы АKУ}

Матрица АКУ в системе МРТ необходима для зажигания заданной последовательности одиночных пикселей посредством включения/выключения автоэмиссионного тока с выбранных автокатодов. Каждый элемент матрицы АКУ отвечает за формирование одиночного пикселя топологического рисунка на подложке применительно к задачам рентгеновской нанолитографии. При построении топологических рисунков различного вида предполагается включать отдельные элементы из матрицы АКУ, в то время как остальные элементы остаются в выключенном состоянии. Массив наноразмерных острийных автокатодов, управляемых шинами сеточных электродов в составе АКУ, изготавливался следующим образом. Легированные фосфором кремниевые пластины с ориентацией (100) и диаметром $150 \mathrm{~mm}$ окислялись в кислороде с парами воды (толщина формирующегося слоя $\mathrm{SiO}_{2} 0.3 \mu \mathrm{m}$ ), затем на них осаждался слой $\mathrm{Si}_{3} \mathrm{~N}_{4}$ в качестве маски толщиной $0.1 \mu \mathrm{m}$, после чего проводилась фотолитография для формирования $T$-образных столбиков в качестве заготовок для кремниевых наноострий. Профиль острия формировался с использованием плазмохимического травления в смеси $\mathrm{SF}_{6}$ и $\mathrm{O}_{2}$ с коэффициентом анизотропии 2.5. Процедура окисления катода проводилась в сухом кислороде, после чего $\mathrm{SiO}_{2}$ стравливался вместе со слоем маски. На рис. 2 представлены фотографии автоэмиссионных структур, полученных в результате проведения вышеописанных технологических операций: массив наноразмерных кремниевых острий с нанометровым радиусом скругления на вершине и АКУ на их основе с управляющей сеточной шиной.

\section{2. Описание технологии формирования матрицы анодных узлов}

Матрица анодных узлов в составе системы МРТ предназначена для генерации рентгеновского излучения в отверстиях прострельной мишени, расположенных напротив „включенных“ АКУ, с пространственным разрешением, соответствующим их диаметру. Для этой цели утоненная кремниевая пластина толщиной $400 \mathrm{~nm}$ окисляется, далее на $\mathrm{SiO}_{2}$ осаждается пленка $\mathrm{TiN}$ толщиной $20 \mathrm{~nm}$ в качестве защитного слоя, препятствующего травлению бериллиевой мембраны при последую- 


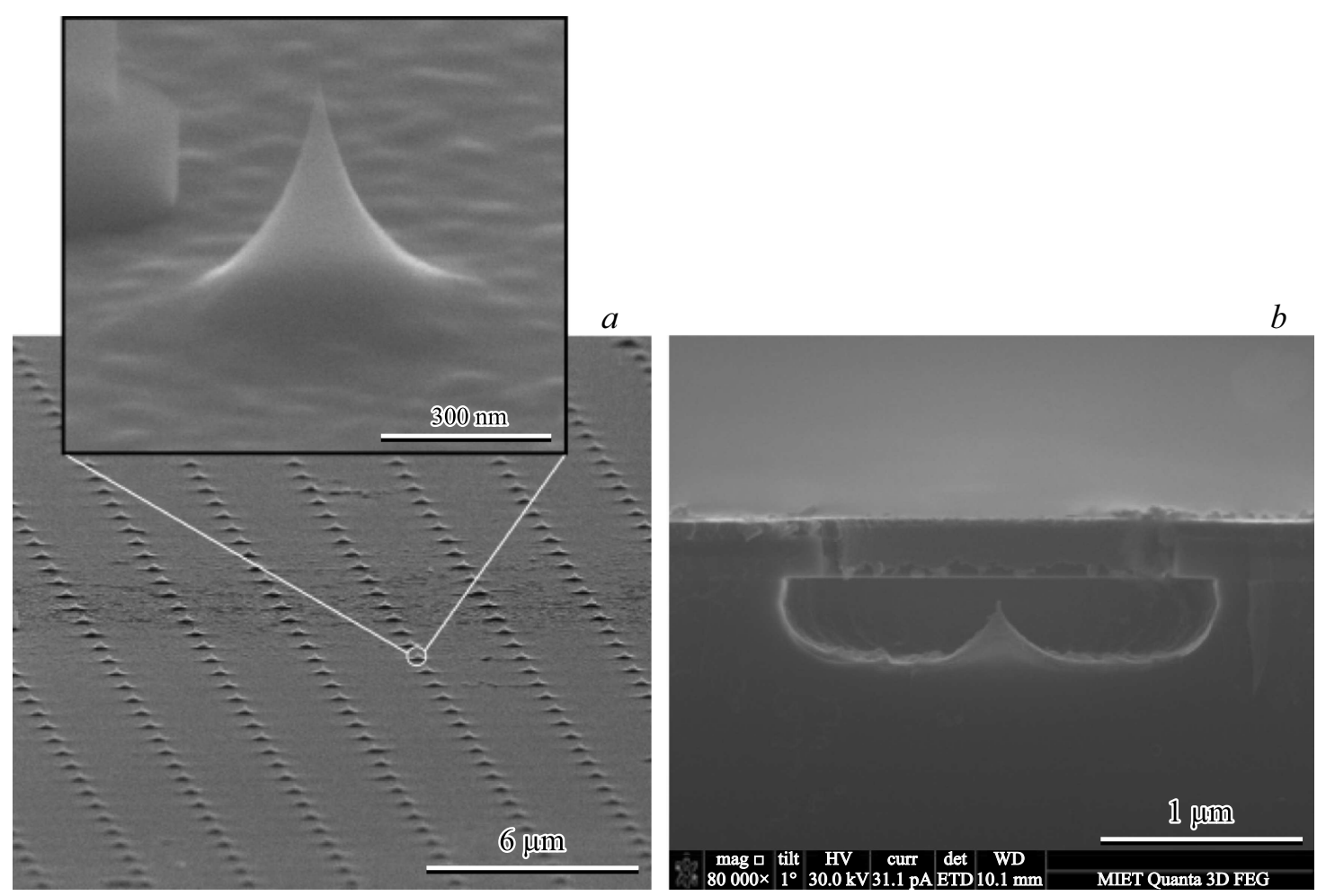

Рис. 2. Изображения (a) матрицы кремниевых автоэмиссионных нанокатодов и поперечного сечения АКУ на их основе (b), полученные на РЭМ.

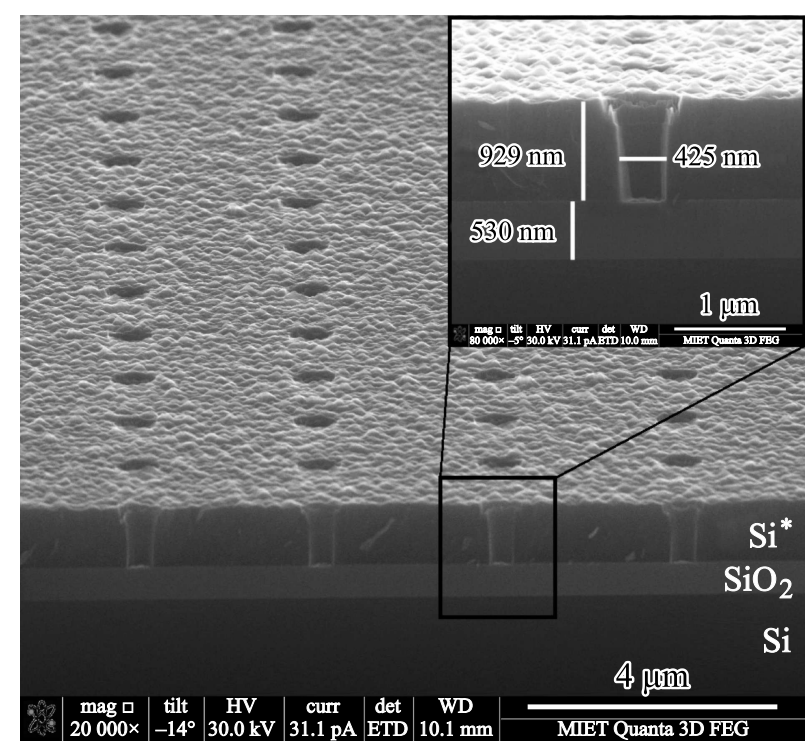

Рис. 3. Изображение заготовки для матрицы анодных узлов до напыления прострельной мишени $(\mathrm{Be})$, состоящей из рентгенопрозрачной мембраны $\left(\mathrm{Si} / \mathrm{SiO}_{2}\right)$ и слоя поликремния $\left(\mathrm{Si}^{*}\right)$ с набором отверстий, полученное на РЭМ.

щих операциях удаления $\mathrm{SiO}_{2}$ и травления поликремния $\left(\mathrm{Si}^{*}\right)$. После этого на пластину напыляется слой бериллия толщиной $200 \mathrm{mn}$, затем на бериллий осаждается $30 \mathrm{~nm}$ слоя TiN, на который сверху осаждается $450 \mathrm{~nm}$
$\mathrm{Si}^{*}$. Далее проводится фотолитография по поликремнию, bosch-процессом травятся с обратной стороны широкие углубления с диаметром поперечного сечения порядка $400 \mathrm{mn}$ (см. на вставке к рис. 3) в местах, расположенных напротив кремниевых нанокатодов на лицевой стороне пластины до слоя $\mathrm{SiO}_{2}$. Для формирования конечной структуры матрицы анодных узлов далее в $\mathrm{XeF}_{2}$ убираются остатки кремния на мембране (micrograss), производится жидкостное химическое травление $\mathrm{SiO}_{2}$ и стравливаются защитные слои TiN. Изображение заготовки для матрицы анодных узлов до напыления слоя бериллия представлено на рис. 3. Предполагается, что выбор толщины бериллиевой мембраны, равной $200 \mathrm{~nm}$, позволяет обеспечить ее улучшенные механические и тепловые свойства.

\section{3. Описание процесса сборки системы МРТ}

Для корректной работы системы МРТ при совмещении матрицы АКУ и матрицы анодных узлов необходимо выполнить следующие условия: 1) точность совмещения должна быть не хуже $1 \mu \mathrm{m} ; 2$ ) должна отсутствовать проводимость между анодной и катодной частью; 3 ) расстояние от катодной до анодной частей должно составлять порядка $10 \mu \mathrm{m}$. Для реализации данной задачи лучше всего подходит процесс сращивания пластин с промежуточным слоем BrewerBONDß 305. Технология совмещения матрицы АКУ и матрицы анодных узлов включает в себя следующие этапы: подготовка пластины 


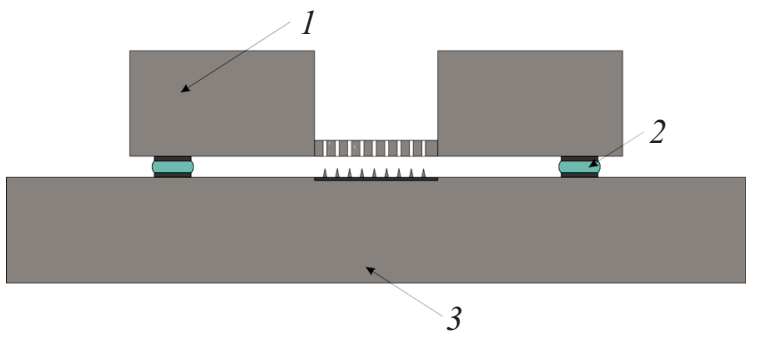

Рис. 4. Система МРТ, полученная в результате склеивания матрицы АКУ и матрицы анодных узлов, где в обозначениях 1 - матрица анодных узлов, 2 - припой, 3 - матрица АКУ.

с матрицей АКУ; нанесение слоя BrewerBONDß 305 толщиной $10-15 \mu \mathrm{m}$ на пластину с матрицей АКУ; фотолитография пластины с матрицей АКУ по нанесенному промежуточному слою; подготовка пластины с матрицей анодных узлов; совмещение пластин с матрицей АКУ и матрицей анодных узлов в установке для сращивания пластин. В результате проведения операций получается система МРТ, представленная на рис. 4.

\section{4. Схема управления элементами матрицы AKY}

Ранее в работе [8] нами была представлена квантовомеханическая модель расчета тока автоэлектронной эмиссии с наноразмерного полупроводникового катода произвольной формы с учетом его теплового разогрева электрическим полем, которая позволила отчасти объяснить отличие измеряемых экспериментально автоэмиссионных токов от их теоретических значений, полученных в рамках теории Фаулера-Нордгейма [9]. Согласно модели Зонга [10], изгиб зон $V_{S}(x, y, z)=-\phi_{S}(x, y, z) / e$, обусловленный проникновением электрического поля в приповерхностный слой кремниевого эмиттера с легированием $n$-типа, определяется решением уравнения Пуассона

$$
\frac{d^{2} \eta_{\varphi}}{d r_{\delta^{2}}}+\frac{2}{r_{\delta}} \frac{d \eta_{\varphi}}{d r_{\delta}}=f\left(\eta_{\varphi}, N_{a}, N_{d}\right)
$$

где - потенциальная энергия, $\eta_{\varphi}=\phi_{S} / k_{B} T, r_{\delta}=r / \delta$, $r=\sqrt{x^{2}+y^{2}+z^{2}}, \quad \delta=\left(\xi \varepsilon_{0} k_{B} T / 2 n_{i} e^{2}\right)^{1 / 2}-$ глубина экранирования Дебая в кремнии, $\xi$ - диэлектрическая постоянная кремнии, $\varepsilon_{0}-$ электрическая постоянная, $k_{B}$ - постоянная Больцмана, $T$ - температура разогрева эмиттера, $e-$ заряд электрона, $n_{i}$ концентрация электронов (дырок) в собственном полупроводнике. В правой части уравнения (1) функция $f\left(\eta_{\varphi}, N_{a}, N_{d}\right)=$ $=\left[\Phi\left(\eta_{\varphi}^{B}, \eta_{\varphi}, \varphi_{\varepsilon}^{F}, \varphi_{\varepsilon}^{v}\right)\right]$ в случае полной ионизации примесей, где $N_{a(d)}$ - концентрация акцепторной (донорной) примеси, $\eta_{\varepsilon}^{F}=\varepsilon_{F} / k_{B} T, \eta_{\varepsilon}^{v(c)}=\varepsilon_{v(c)}, \eta_{\varphi}^{B}=\sinh ^{-1}\left(\left(N_{a}-\right.\right.$ $\left.\left.-N_{d}\right) / 2 n_{i}\right)=\varphi_{B} / k_{B} T, \varphi_{B}=\varepsilon_{F i}-\varepsilon_{F}, \varepsilon_{F i}-$ уровень $\Phi$ ерми в собственном полупроводнике, $\varepsilon_{F}-$ уровень Ферми, $\varepsilon_{v(c)}$ дно валентной зоны (зоны проводимости),
Схема переключения состояния элементов матрицы АКУ (при напряжении на мишени $3 \mathrm{kV}$ )

\begin{tabular}{l|c|c}
\hline $\begin{array}{l}\text { Состояние } i-j \text {-элемента } \\
\text { матрицы АКу }\end{array}$ & Выключено & Включено \\
\hline Выбранная $i$-я сеточная шина (V) & 0 & 15 \\
\hline Выбранная $j$-я катодная шина (V) & \multicolumn{2}{|c}{30} \\
\hline Остальные сеточные шины (V) & \multicolumn{2}{|c}{0} \\
\hline Остальные катодные шины (V) & 30 & -30
\end{tabular}

а $\Phi=\Phi\left(\eta_{\varphi}^{B}, \eta_{\varphi}, \eta_{\varphi}^{2}, \eta_{\varphi}^{v}, \eta_{\varphi^{c}}\right)$ - функция, рассчитываемая через интегралы Ферми 1/2 порядка. При расчете (1) используется граничное условие $d \eta_{\varphi} / d r_{\delta}\left(r_{\delta} \rightarrow-\infty\right)=0$. Стоит учесть, что разогрев кремниевого нанокатода при протекании тока эмиссии учитывается через выполнение граничного условия на поверхности кремниевого эмиттера [11]:

$$
J=\sigma \nabla V_{S} \cdot \mathbf{e}_{\mathrm{n}},
$$

где $\sigma=\sigma(x, y, z, T)$ - зависящая от температуры и размеров электропроводность эмиттера, $\mathbf{e}_{\mathrm{n}}-$ единичный вектор, перпендикулярный поверхности эмиттера, рассчитывается из уравнения (1) через параметр $\eta_{\varphi}$, а плотность тока эмиссии в (2) определяется уравнением Фаулера-Нордгейма [12]:

$$
J=\frac{A_{0} E^{2-v}}{\phi t_{0}^{2}}\left(\frac{\phi^{2} \exp (6)}{4 Q}\right)^{v} \exp \left(-B_{0} \frac{\phi^{3 / 2}}{E}\right),
$$

где $\quad A_{0}=e / 16 \pi^{2} \hbar, \quad B_{0}(4 / 3 \hbar) \sqrt{2 m_{e}}, \quad v=2 B_{0} Q / 3 \sqrt{\phi}$, $m_{e}$ - масса электрона, $\hbar$ - постоянная Планка, $Q=e^{2} / 16 \pi \varepsilon_{0}, t_{0}=1+1 /(6 \exp (1)), E-$ электрическое поле на поверхности эмиттера. При интегрировании уравнения (3) по всей эффективной площади эмиссии $S_{\text {eff }}$ получим ток, т.е. $I=\int J d S \approx J S_{\text {eff. }}$ На рис. 5 представлена вольт-амперная характеристика (ВАХ), снятая в диодном режиме с единичного кремниевого нанокатода, теоретически рассчитанная, согласно формуле (3), для случая межэлектродного расстояния, равного $10 \mu \mathrm{m}$ при напряжении на катоде $30 \mathrm{~V}$, напряжение на аноде $3 \mathrm{kV}$. Полагая, что включение тока происходит при электрическом поле порядка $E=E_{c r}=3-3.1 \mathrm{~V} / \mathrm{nm}$, на основе представленной модели была проведена оценка пороговых управляющих напряжений на сетке, необходимых для включения/выключения тока эмиссии в элементе матрицы АКУ, геометрические размеры которого взяты в соответствии с рис. 2 (где представлено РЭМ изображение его поперечного сечения), а также разработана схемотехническая и топологическая библиотека элементов для считывания электрического сигнала. Из рис. 5 хорошо видно, что значение $E_{c r}$ достигается при напряжении на сетке, равном около $15 \mathrm{~V}$. Таблица иллюстрирует схему переключения $i-j$-элементов матрицы АКУ, что необходимо для зажигания заданной конфигурации пикселей топологического рисунка, 


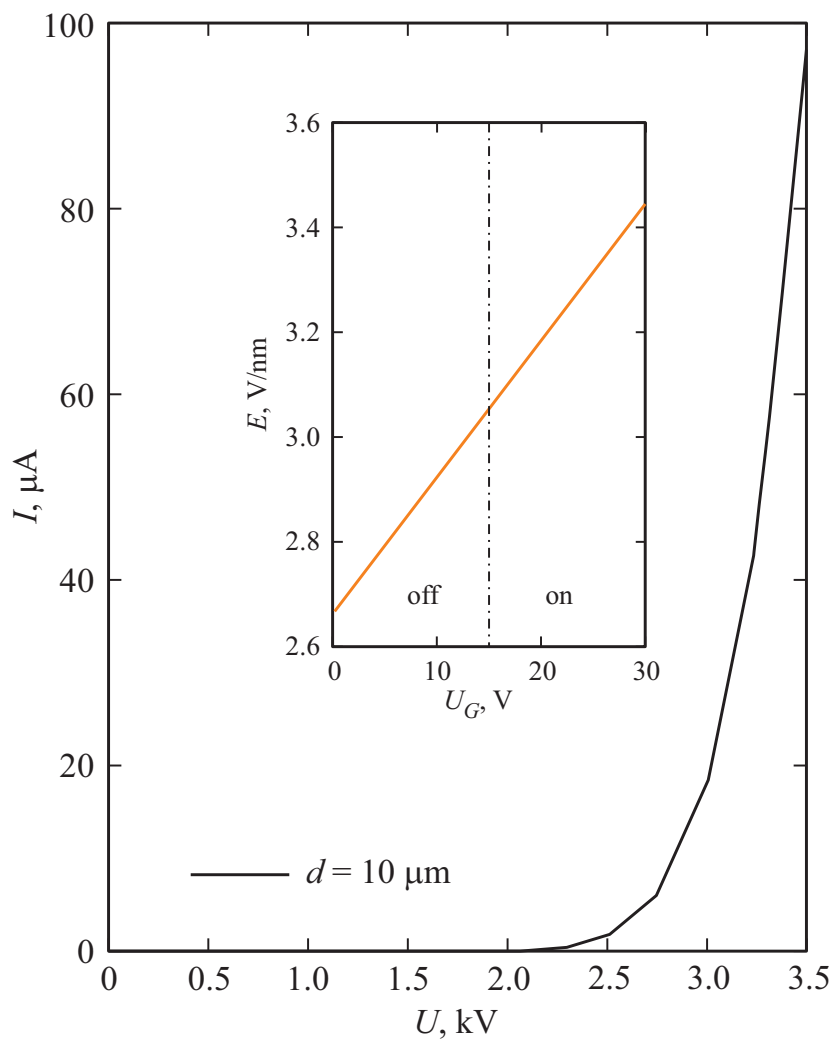

Рис. 5. ВАХ с одиночного кремниевого нанокатода, рассчитанная по формуле (3) при межэлектродном расстоянии $10 \mu \mathrm{m}$ и напряжении на аноде $3 \mathrm{kV}$. На вставке - зависимость напряженности электрического поля на вершине нанокатода от напряжения на сеточном электроде при тех же параметрах.

формируемого на подложке, играющей роль анода, с использованием системы МРТ. Вариация напряжения на $i$-ой шине сеточного электрода с 0 до $15 \mathrm{~V}$ включает отдельный $i-j$-элемент АКУ в составе матрицы при напряжении на $j$-ой катодной шине $30 \mathrm{~V}$, в то время как на остальных катодных шинах напряжение равно $-30 \mathrm{~V}$. При этом напряжение на прострельной мишени (аноде) задается равным $3 \mathrm{kV}$. В этом случае, когда расстояние от катода до анода фиксируется на уровне $10 \mu \mathrm{m}$, характерный размер пятна на мишени от единичного нанокатода составляет около $2 \mu \mathrm{m}$, что покрывает пространственную область генерации рентгеновского пучка в месте локализации отверстия в рентгенопрозрачной мембране (рис. 3).

\section{2. Методика эксперимента}

Измерение автоэмиссионных характеристик катодной части устройства (пластина с матрицей АКУ) было осуществлено с применением многоканальной компьютеризированной установки с высоковольтным вакуумным постом [13].

В установке импульсным источником на образец подается полусинусоидальный импульс напряжения с частотой $50 \mathrm{~Hz}$ (т.е. полпериода - отрицательный импульс по напряжению синусоидальной формы, полпериода - нулевое напряжение), после чего регистрируется профиль соответствующего импульса автоэмиссионного тока, что позволяет каждые $20 \mathrm{~ms}$ записывать ВАХ с матрицы АКУ. Данный подход позволяет получать характеристики повышенной гладкости, отличающиеся от характеристик, полученных в режиме медленного сканирования постоянным напряжением. Взаимосвязь быстрых ВАХ и медленных была изучена ранее в работе [14]. Высокая скорость регистрации ВАХ в совокупности с разработанной методикой онлайнобработки данных обеспечивает возможность расчета не только эффективных характеристик катода (коэффициент усиления поля $\beta_{\text {eff }}$ и площадь эмиссии $\left.S_{\text {eff }}\right)$, но и их стохастического разброса, который характеризует степень изменчивости ВАХ и является одной из причин временной нестабильности эмиссионного тока. Эффективные параметры рассчитываются известным методом построения прямой линии тренда к ВАХ в полулогарифмических координатах Фаулера-Нордгейма. Для вывода взаимосвязи эффективных параметров $\beta_{\text {eff }}$ и $S_{\text {eff }}$ с наклоном $(K)$ и отсечкой $(S)$ линии тренда мы использовали уравнение полевой эмиссии в аннотации Элинсона-Шредника [15], приведенное к макроскопическим величинам тока $I$ и напряжения $U$ и записанное в единицах СИ: $I=S_{\text {eff }} A_{\phi}\left(U \beta_{\mathrm{eff}} / d\right) \exp \left(-B_{\phi} d / U \beta_{\mathrm{eff}}\right)$, где соответствующие переменные в формуле тока $A_{\phi}=1.4 \cdot 10^{-6}\left[A \cdot e V \cdot V^{2}\right] \exp \left(10.17 / \phi^{1 / 2}\right) / \phi, \quad B_{\phi}=$ $=6.49 \cdot 10^{9}\left[\mathrm{eV}^{-3 / 2} \cdot V / \mathrm{m}\right] \phi^{3 / 2}, \quad \phi-$ работа выхода материала эмиттера, $d-$ межэлектродное расстояние. В полулогарифмических координатах это уравнение принимает вид: $\ln \left(I / U^{2}\right)=\ln \left(\beta_{\text {eff }}^{2} A_{\phi} S_{\text {eff }} / d^{2}\right) B_{\phi} d / U \beta_{\text {eff }}=$ $=S+K / U$. Тогда эффективные параметры можно рассчитать по следующим формулам:

$$
\beta_{\text {eff }}=B_{\phi} d / K, \quad S_{\text {eff }}=\exp (S) d^{2} / A_{\phi} \beta_{\text {eff }}^{2}
$$

\section{3. Экспериментальные результаты}

Построение экспериментальной ВАХ в полулогарифмических координатах Фаулера-Нордгейма и аппроксимация ее прямолинейной зависимостью позволяют рассчитать значения эффективных параметров: коэффициента усиления поля и площади эмиссии. Это два основных параметра, которые характеризуют эффективность работы автоэмиссионного нанокатода. На рис. 6 представлена экспериментальная BAX в обычных координатах и в координатах Фаулера-Нордгейма, а также аппроксимирующие их модельные кривые. Данные результаты получены при межэлектродном расстоянии $300 \mu \mathrm{m}$ в условиях технического вакуума $\left(10^{-5} \mathrm{~Pa}\right)$. Выбор такого расстояния в эксперименте необходим для предотвращения достижения высоких токов и перегрева на аноде. Из рисунка легко видеть, что при напряжении на аноде от $3 \mathrm{kV}$ и выше матрица АКУ позволяет получить 


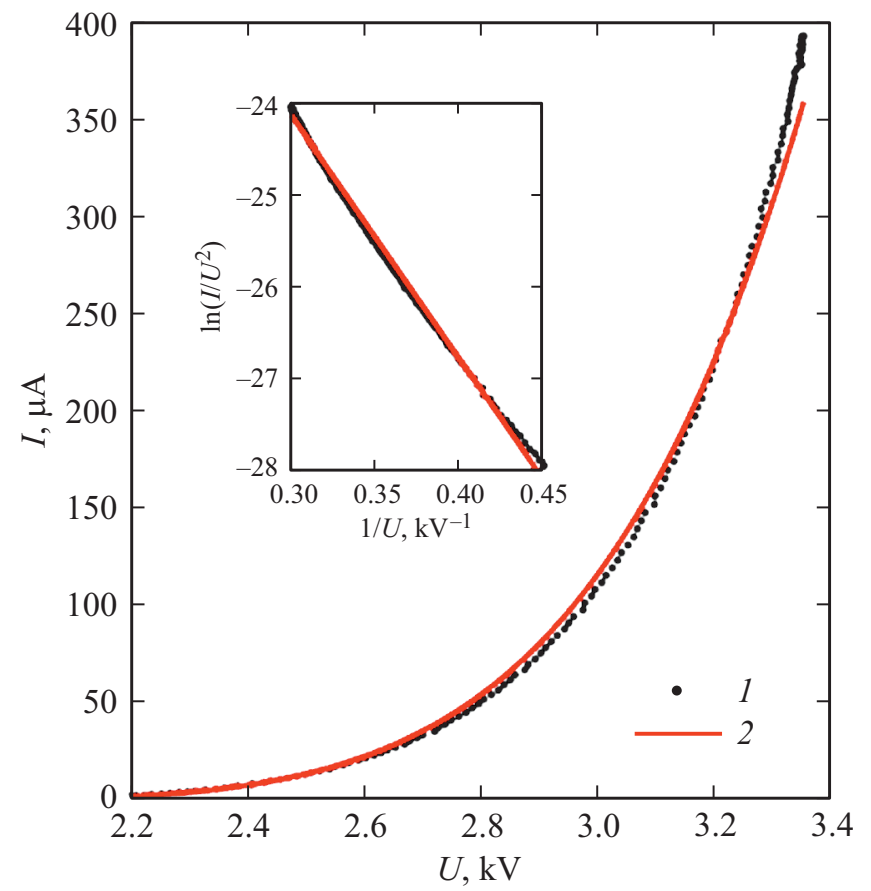

Рис. 6. ВАХ, снятая с матрицы кремниевых автоэмиссионных нанокатодов, в обычных координатах и координатах Фаулера-Нордгейма (см. вставку), где 1 - экспериментальные кривые, 2 - аппроксимирующие кривые, построенные по эффективным параметрам.

автоэмиссионный ток более $100 \mu \mathrm{A}$. Предполагается, что при таком напряжении и токе в матрице анодных узлов будет формироваться рентгеновское излучение с коэффициентом конверсии на уровне порядка $10^{-4}$, расчеты которого были проведены ранее в работе [6]. Оценка эффективных коэффициента усиления поля $\beta_{\text {eff }}$

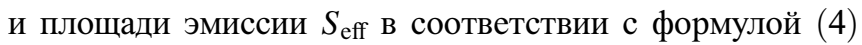
дала следующие результаты: $\beta_{\text {eff }}=250$ (в безразмерных единицах $), S_{\text {eff }}=340 \mathrm{~nm}^{2}$. Величина имеет порядок величины, характерный для нанокатодов такого рода. Она характеризует степень увеличения поля на вершине катода за счет его форм-фактора.

\section{Заключение}

Таким образом, в работе подробно рассмотрены основные технологические принципы создания системы МРТ на основе совмещения матрицы АКУ на основе кремниевых автоэмиссионных нанокатодов и матрицы анодных узлов в качестве составной части прострельной мишени. Представлены результаты технологической реализации отдельных элементов системы МРТ, в частности, матрицы АКУ и матрицы анодных узлов, с применением базовых операций кремниевой МЭМС технологии. Описана методика снятия BAX с матрицы кремниевых острийных автокатодов, предназначенная для записи измеряемых сигналов и последующей обработки получаемых сведений об их эмиссионных свойствах в режиме реального времени. Показано, что в режиме полевой эмиссии при напряжении порядка $3 \mathrm{kV}$ с матрицы наноразмерных кремниевых эмиттеров собирается ток, равный $100 \mu \mathrm{A}$. Как показано в [6], соответствующая такой величине тока эмиссии плотность мощности на матрице анодных узлов будет превышать $1 \mathrm{~W} / \mathrm{cm}^{2}$, что достаточно для эффективной конверсии энергии электронов в мягкое рентгеновское излучение. Следующим шагом в разработке системы МРТ на базе матрицы АКУ является поиск оптимальных параметров генерации рентгеновского излучения в матрице анодных узлов. Использование указанных технологических решений по созданию элементов системы МРТ в совокупности с применением высокоэффективной рентгеновской оптики открывает путь к развитию рентгеновской нанолитографии для создания структур с размером до $20 \mathrm{~nm}$ и ниже [16].

\section{Финансирование работы}

Работа выполнена коллективом авторов, в который входят Н.А. Дюжев, Г.Д. Демин, Н.А. Филиппов, И.Д. Евсиков, П.Ю. Глаголев, М.А. Махиборода, Н.И. Чхало, Н.Н. Салащенко, с использованием оборудования Центра коллективного пользования „Микросистемная техника и электронная компонентная база“ Национального исследовательского университета „Московский институт электронной техники“, поддержанного Минобрнауки России, при поддержке Минобрнауки России в рамках работ по проекту 14.578.21.0250, RFMEFI57817X0250 с использованием Центра НТИ „Сенсорика“.

\section{Конфликт интересов}

Авторы заявляют, что у них нет конфликта интересов.

\section{Список литературы}

[1] Guerrera S.A., Akinwande A.I. // Nanotech. 2016. Vol. 27. P. 295302. DOI: $10.1088 / 0957-4484 / 27 / 29 / 295302$

[2] Wang S.F., Chiang H.Y., Liao Y.J., Liu R.S., Cheng C.C., Yang H.W., Wang S.W., Lin Y.C., Hsu S.M. // Radiat. Phys. Chem. 2019. Vol. 158. P. 188. DOI: 10.1016/j.radphyschem.2019.02.005

[3] Demin G.D., Djuzhev N.A., Filippov N.A., Glagolev P.Yu., Evsikov I.D., Patyukov N.N. // J. Vac. Sci. Technol. B. 2019. Vol. 37. P. 022903. DOI: $10.1116 / 1.5068688$

[4] Djuzhev N.A., Demin G.D., Gryazneva T.A., Pestov A.E., Salashchenko N.N., Chkhalo N.I., Pudonin F.A. // Lebedev Phys. Inst. 2018. Vol. 45. N 1. P. 1. DOI: $10.3103 / \mathrm{S} 1068335618010013$

[5] Salashchenko N.N., Chkhalo N.I., Djuzhev N.A. // J. Surf. Invest.: X-Ray, Synchrotron Neutron Tech. 2018. Vol. 10. P. 10. DOI: $10.1134 / \mathrm{S} 1027451018050324$

[6] Lopatin A.Ya., Par'ev D.E., Pestov A.E., Salashchenko N.N., Chkhalo N.I., Demin G.D., Dyuzhev N.A., Makhiboroda M.A., Kochetkov A.A. // JETP. 2018. Vol. 127. N 6. P. 985. DOI: $10.1134 / \mathrm{S} 1063776118100175$ 
[7] Chkhalo N.I., Salashchenko N.N. // AIP Adv. 2013. Vol. 3. P. 082130. DOI: $10.1063 / 1.4820354$

[8] Djuzhev N.A., Demin G.D., Glagolev P.Yu., Makhiboroda M.A., Patyukov N.N. / Proc. 2018 31st International Vacuum Nanoelectronics Conference. Kyoto, Japan, 2018. P. 116. DOI: 10.1109/IVNC.2018.8520046

[9] Forbes R.G. / Proc. 2018 31st International Vacuum Nanoelectronics Conference. Kyoto, Japan, 2018. P. 126. DOi: 10.1109/IVNC.2018.8520077

[10] Tsong T.T. // Surf. Sci. 1979. Vol. 85. P. 1. DOI: 10.1016/0039-6028(79)90228-0

[11] Eimre K., Aabloo A., Djurabekova F., Zadin V. // J. Appl. Phys. 2015. Vol. 118. P. 033303. DOI: $10.1063 / 1.4926490$

[12] Jensen K.L. Introduction to the physics of electron emission. Wiley \& Sons Ltd. 2018, 712 p.

[13] Popov E.O., Kolosko A.G., Filippov S.V., Romanov P.A., Fedichkin I.L. // Mater. Today: Proc. 2018. Vol. 5. N 5. P. 13800. DOI: 10.1016/j.matpr.2018.02.021

[14] Popov E.O., Kolosko A.G., Filippov S.V., Romanov P.A., Terukov E.I., Shchegolkov A.V., Tkachev A.G. // Appl. Surf. Sci. 2017. Vol. 424. P. 239. DOI: 10.1016/j.apsusc.2017.04.120

[15] Elinson M.I. (Ed.) The cold cathodes. M.: Sov. Radio, 1974. $336 \mathrm{p}$.

[16] Maldonado J.R., Peckerar M. // Microelectron. Eng. 2016. Vol. 161. P. 87. DOI: 10.1016/j.mee.2016.03.052 